\title{
Effects of topical mitomycin C on primary trabeculectomies and combined procedures
}

Vital P Costa, Marlene R Moster, Richard P Wilson, Courtland M Schmidt, Sai Gandham, Maura Smith

\begin{abstract}
The charts were reviewed of all patients who underwent primary trabeculectomies (group 1) or combined procedures (phacoemulsification +intraocular lens implantation + trabeculectomy - group 2) and received intraoperative mitomycin C $(0.4 \mathrm{mg} / \mathrm{ml})$ between 1991 and 1992 at Wills Eye Hospital. A total of 54 eyes of 54 patients were included: 39 in group 1 and 15 in group 2 . Intraocular pressure was controlled successfully in $97.4 \%$ of eyes in group 1 (mean follow up 6.7 months), and in $93.3 \%$ in group 2 (mean follow up 6.8 months). Main complications included choroidal detachment $(n=15)$, shallow anterior chamber $(n=9)$, cataract formation $(n=8)$, and hypotony maculopathy $(n=3)$. The use of mitomycin $\mathbf{C}$ in primary trabeculectomies and combined procedures is associated with high success rates. However, it may be associated with unacceptable risks of vision threatening complications related to excessive filtration.
\end{abstract}

(Br F Ophthalmol 1993; 77: 693-697)

The modulation of wound healing is desirable to increase the success rate of glaucoma filtration surgery, particularly in eyes with poor surgical prognosis. 5-Fluorouracil (5-FU) was the first antimetabolite drug used to inhibit fibroblast proliferation and prevent scarring of the filtration bleb after glaucoma filtering surgery. ${ }^{1-4}$ However, its use is associated with some disadvantages, including frequent dosing, discomfort with injections, corneal epithelial defects, and conjunctival wound leaks. ${ }^{1-4}$ Severe, often permanent, complications such as corneal ulceration, opacification, and perforation have also been reported after 5-FU injections. ${ }^{3}$

Mitomycin C is an alkylating agent isolated from the broth of Streptomyces caespitosus which interrupts DNA replication and inhibits mitosis. $^{56}$ It has been shown to inhibit the proliferation of cultured rabbit subconjunctival fibroblasts in a dose dependent way with a potency 100 times higher than 5-FU. ' Initially, it was used after pterygium excision to prevent its recurrence..$^{8-13}$ Recently, mitomycin $\mathrm{C}$ has been shown to be highly effective in preventing scar formation after glaucoma filtration surgery in animal and human eyes. ${ }^{14-21}$

This study describes the results of topical intraoperative mitomycin $\mathrm{C}$ in eyes that had undergone primary trabeculectomies or combined procedures.

Materials and methods

We reviewed the charts of all patients who underwent primary trabeculectomies or combined procedures and received the intraoperative application of mitomycin $\mathrm{C}$ between 1 October, 1991 and 30 April 1992 at the glaucoma service of Wills Eye Hospital. We randomly selected one eye of patients in whom bilateral surgeries were performed to participate in the study. The patients were divided into two groups according to the indications for mitomycin $\mathrm{C}$ use.

Group 1 or primary trabeculectomy group. This group included patients with advanced uncomplicated glaucoma (primary open angle, low tension, chronic angle closure, pseudoexfoliation, or pigmentary glaucomas), who had never undergone a filtration procedure but who had shown progressive glaucomatous damage at high normal intraocular pressure (IOP) (between 17 and $20 \mathrm{~mm} \mathrm{Hg}$ ), and required very low IOP after surgery.

Group 2 combined procedure group. This group included patients with advanced glaucomatous damage or with refractory glaucoma who underwent combined procedures (phacoemulsification+posterior chamber intraocular lens implantation + trabeculectomy.

All the patients went through a complete preoperative ophthalmic examination (less than 1 month before surgery) including best corrected visual acuity measurement, biomicroscopy, tonometry with a Goldmann applanation tonometer, direct and indirect ophthalmoscopy. Informed consent was obtained from all patients.

Trabeculectomies were performed in all eyes by three of us (RPW, MRM, CMS), using a modified technique based on the original procedure developed by Cairns. ${ }^{22}$ When trabeculectomy alone was indicated, a limbus based conjunctival flap was performed approximately $9 \mathrm{~mm}$ posterior to the limbus. For combined procedures, a limbus or a fornix based conjunctival flap was employed. A Weck cell sponge (Alcon Surgical, Fort Worth, Texas) was cut in half and then trimmed to a $4 \times 3 \mathrm{~mm}$ size. The sponge was then soaked with a $0.4 \mathrm{mg} / \mathrm{m}$ solution of mitomycin $\mathrm{C}$ and placed in contact with the exposed scleral bed and overlying Tenon's/conjunctival flap for 1.5 to 2.5 minutes in group 1 (according to the age and thickness of the Tenon's), and for 3.5 minutes in group 2. Subsequently, the sponge was removed and the area was copiously irrigated with $30 \mathrm{ml}$ of balanced salt solution (Allergan Medical Optics, Irvine, California). The scleral flap was then dissected with a 67 blade (Alcon Surgical, Fort Worth, Texas). After the corneoscleral block of tissue was excised and a peripheral iridectomy was performed, the scleral flap was tightly closed with two to four 10-0 monofilament nylon 
sutures (Ethicon, Somerville, New Jersey) (and, in some cases, with releasable sutures), in such a manner that the anterior chamber remained formed allowing a slow leak of aqueous from the edge of the flap. In the event of simultaneous cataract surgery, phacoemulsification was done under the scleral flap, followed by the insertion of an intraocular lens within the capsular bag and removal of the corneoscleral block. The anterior chamber was reformed through a paracentesis previously done with a 27 gauge needle and the conjunctival wound was closed with either a 10-0 nylon or 8-0 Vycril suture (Ethicon, Somerville, New Jersey). Following surgery, $0.5 \mathrm{ml}$ of triamcinolone (Westwood-Squibb Pharmaceuticals Inc, Buffalo, New York) and $0.5 \mathrm{ml}$ of gentamicin (Lyphomed, Deerfield, Illinois) were injected subconjunctivally.

Visual acuity and IOP measurements were made 1 week, 2 weeks, 1 month, 3 months, 6 months, and at the last available follow up. Visual acuity change was considered significant when a change of 2 or more Snellen lines or one low vision category (that is, hand motions to light perception) was observed from preoperative values.

Before the data collection, successful IOP control was defined as complete when IOP was $\leqslant 21 \mathrm{~mm} \mathrm{Hg}$ without medication. A qualified success was an IOP between 22 and $25 \mathrm{~mm} \mathrm{Hg}$ without medication or when IOP was $\leqslant 21 \mathrm{~mm}$ $\mathrm{Hg}$ with medication. Failure was defined as IOP $>25 \mathrm{~mm} \mathrm{Hg}$ without medication, IOP $>21 \mathrm{~mm}$ $\mathrm{Hg}$ with medication, or when further glaucoma surgery was indicated. Patients in whom preoperative IOP was $\leqslant 21 \mathrm{~mm} \mathrm{Hg}$ were classified as complete successes when the IOP was reduced by at least $30 \%$ of the preoperative measurement without the use of antiglaucoma medications, or qualified when a similar amount of IOP reduction was obtained with medication. Only eyes with at least 6 months of follow up were included for the analysis of IOP control.

Postoperative complications of all patients were recorded. The analysis of complications included all patients, regardless of the length of follow up. Special attention was directed to the diagnosis of conjunctival wound leak, corneal erosion, hypotony maculopathy, shallow anterior chamber, and choroidal detachment. Shallow anterior chambers were graded according to the following classification:

Grade 1, peripheral iridocorneal touch

Grade 2, peripheral+central iridocorneal touch

Grade 3, totally flat, including lens-corneal touch

Indications for drainage of choroidal detachments included grade 3 shallow anterior chambers or shallow anterior chambers with flat blebs for 4 or more days post surgery.

Results are expressed as mean (SD). Comparisons were made with paired Student's $t$ tests. $p$ Values of less than $\mathbf{0 . 0 5}$ were considered significant.

\section{Results}

Seventy three eyes of 71 patients underwent filtration surgeries with topical intraoperative mitomycin $\mathrm{C}$ during the study interval. Fifty three eyes of 51 patients underwent primary trabeculectomies (group 1), and 20 eyes of 20 patients underwent combined procedures (group 2). Only one eye of the two patients who underwent bilateral surgeries was randomly selected to be included in the analysis. Among the 71 remaining eyes, a total of 54 eyes of 54 patients had a minimum follow up of 6 months: 39 in group 1 , and 15 in group 2.

Preoperative data of the 54 eyes with at least 6 months of follow up are displayed in Table 1. Among the 15 eyes of group 2, four eyes were at high risk for failure of the filtering procedure, due to inflammatory glaucoma (two cases), previous filtration surgery (one case), and phacolytic glaucoma (one case).

Table 2 shows the mean IOPs at all time intervals in groups 1 and 2, as well as the mean number of antiglaucoma medications used at the last available follow up. After a mean follow up of $6.7(0.7)$ months, mean IOP in the primary traceculectomy group (group 1) was $9 \cdot 8$ (3.9) $\mathrm{mm} \mathrm{Hg}$. Eyes which underwent combined procedures (group 2) had a mean IOP of 13.0 $(4 \cdot 0)$ after $6 \cdot 8(0 \cdot 9)$ months.

A series of two tailed paired $t$ tests showed that postoperative reductions in IOP were highly significant $(p<0.001)$ at all time intervals in both groups. When we compared the number of antiglaucoma medications used preoperatively and at the last follow up, the reduction observed was also highly significant $(p<0.00001)$ in both groups.

Table 3 shows the success rates of IOP control in each group. After a minimum follow up of 6 months, trabeculectomy with intraoperative mitomycin C successfully controlled IOP in $97.4 \%$ of the cases in group 1 , and in 93.3 of the eyes in group 2 . At the last follow up, seven of the

Table 1 Preoperative data

\begin{tabular}{lll}
\hline Variable & Group $1(n=39)$ & Group 2(n=15) \\
\hline Age (years)(SD) & $69 \cdot 5(9 \cdot 7)$ & $73 \cdot 6(11 \cdot 2)$ \\
Sex (F/M) & $16 / 23$ & $9 / 6$ \\
Race(W/B) & $32 / 7$ & $11 / 4$ \\
IOP(SD) & $27 \cdot 2(8 \cdot 4)$ & $26 \cdot 4(9 \cdot 5)$ \\
Medications (SD) & $2 \cdot 9(0 \cdot 7)$ & $2 \cdot 0(0 \cdot 8)$ \\
Lens status & P39 PSO A0 & P15 PS0 A0 \\
Previous ALT & 29 & 6 \\
Diagnosis & 26 & 5 \\
$\quad$ POAG & 8 & 3 \\
CACG & 4 & 2 \\
Pseudoexfoliation & 1 & 1 \\
$\quad$ Pigmentary & 0 & 2 \\
$\quad$ Inflammatory & 0 & 1 \\
$\quad$ Low tension & 0 & 1 \\
Phacolytic & 0 & \\
\hline
\end{tabular}

$\mathrm{F}=$ female; $\mathrm{M}=$ male; $\mathrm{W}=$ white $\mathrm{B}=$ black; $\mathrm{P}=$ phakic; PS=pseudophakic; $\mathrm{A}=$ aphakic; $\mathrm{ALT}=$ argon laser $\mathrm{PS}=$ pseudophakic; $\mathrm{A}=$ aphakic; $\mathrm{AL} \mathrm{T}=$ argon laser trabeculoplasty; $P O A G=$ primary open angl
$\mathrm{CACG}=$ chronic angle closure glaucoma.

Table 2 Postoperative data

\begin{tabular}{lcc}
\hline Variable & Group 1 $(n=39)$ & Group 2 $(n=15)$ \\
\hline IOP $(\mathrm{mm}$ Hg) & & \\
1 week (SD) & $13 \cdot 2(8 \cdot 3)(\mathrm{n}=35)$ & $9 \cdot 0(5 \cdot 6)(\mathrm{n}=13)$ \\
2 weeks (SD) & $9 \cdot 5(4 \cdot 8)(\mathrm{n}=35)$ & $8 \cdot 7(4 \cdot 3)(\mathrm{n}=13)$ \\
1 month (SD) & $8 \cdot 2(3 \cdot 9)(\mathrm{n}=36)$ & $10 \cdot 7(4 \cdot 5)(\mathrm{n}=13)$ \\
3 months (SD) & $9 \cdot 1(4 \cdot 0)(\mathrm{n}=32)$ & $12 \cdot 2(5 \cdot 5)(\mathrm{n}=9)$ \\
6 months (SD) & $9 \cdot 7(3 \cdot 9)(\mathrm{n}=39)$ & $13 \cdot 1(4 \cdot 0)(\mathrm{n}=15)$ \\
Last visit (SD) & $9 \cdot 8(3 \cdot 9)(\mathrm{n}=39)$ & $13 \cdot 1(4 \cdot 0)(\mathrm{n}=15)$ \\
Medications (SD) & $0 \cdot 1(0 \cdot 2)$ & $0 \cdot 1(0 \cdot 2)$ \\
Last visit & & \\
\hline
\end{tabular}


Table 3 Success rates of intraocular pressure control

\begin{tabular}{lllll}
\hline Group & $\begin{array}{l}\text { Number } \\
\text { of eyes }\end{array}$ & $\begin{array}{l}\text { Complete } \\
\text { success }\end{array}$ & $\begin{array}{l}\text { Qualified } \\
\text { success }\end{array}$ & Total \\
\hline 1 & 39 & $37(94 \cdot 8 \%)$ & $1(2 \cdot 6 \%)$ & $38(97 \cdot 4 \%)$ \\
2 & 15 & $14(93 \cdot 3 \%)$ & $0(0 \cdot 0 \%)$ & $14(93 \cdot 3 \%)$ \\
\hline
\end{tabular}

Table 4 Visual acuity outcome ${ }^{\star}$

\begin{tabular}{llll}
\hline Group & Number of eyes & $\begin{array}{l}\text { Stabilised } \\
\text { or improved }\end{array}$ & Worse \\
\hline 1 & 39 & $28(71 \cdot 8 \%)$ & $11(28 \cdot 2 \%)$ \\
2 & 15 & $15(100 \%)$ & $0(0 \cdot 0 \%)$ \\
\hline
\end{tabular}

$\star$ Change in visual acuity $=$ change of 2 or more Snellen lines or one low vision category (that is, hand motions to light perception) from preoperative values.

Table 5 Postoperative complications

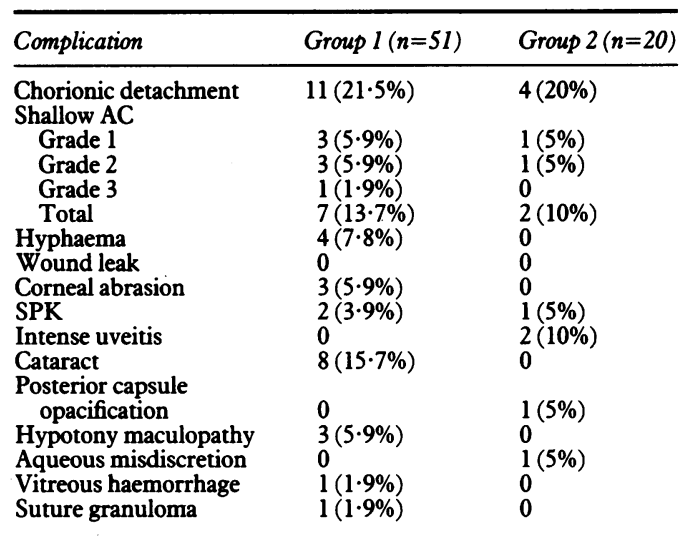

$\mathrm{AC}=$ anterior chamber; $\mathrm{SPK}=$ superficial punctate keratitis.

39 eyes $(17 \cdot 9 \%)$ in the primary trabeculectomy group had IOP lower or equal to $5 \mathrm{~mm} \mathrm{Hg}$. One of 15 eyes in the combined procedure group $(6.6 \%)$ had similar IOPs. Filtering blebs were present in 37 of the 39 cases of group 1 (98.9\%), and 11 of 15 cases in group 2 (73.3\%).

The visual acuity outcome is displayed in Table 4. Group 1 presented the highest incidence of significant visual acuity loss $(28 \cdot 2 \%)$. Cataract formation (in eight of the 11 patients) and hypotony maculopathy (in the remaining three) were responsible for visual acuity loss in group 1 . In group 2, all but two eyes significantly improved their preoperative visual acuities. Postoperative visual acuities of these two eyes did not improve secondary to severe preoperative visual field loss (that is, loss of fixation).

Postoperative complications of all 71 patients who underwent trabeculectomy with intraoperative mitomycin $\mathrm{C}$ are shown in Table 5. Choroidal detachment was the most frequent complication in both groups, followed by shallow anterior chamber. Among the 11 eyes with postoperative choroidal detachment in group 1 , seven showed concomitant shallow anterior chambers and had to be drained. Two of these cases had detachments which either persisted for a long time or developed late in the postoperative period; they were usually difficult to control, requiring more than one drainage. All the four cases of postoperative choroidal detachment in group 2 (two of them showing concomitant shallow anterior chambers) resolved spontaneously.
Corneal abrasions and superficial punctate keratitis were seen in a total of three cases each. Conjunctival wound leak was not observed in this series. Cataract formation was the most frequent late complications (eight of 51 patients in group 1 , or $15.7 \%$ ). Of the eight cases of postoperative lens opacification, four had choroidal detachment and shallow anterior chamber during the early postoperative period.

Hypotony maculopathy developed in a total of three cases. In our series, the mean refractive error (spherical equivalent) was -2.375 dioptres (range $=+2 \cdot 00$ to $-7 \cdot 75$ ), two of the three eyes were myopic and showed a hyperopic shift due to the chorioretinal wrinkling. Two of them were treated with cryotherapy of the bleb (five to seven applications, 30 seconds, $-80^{\circ} \mathrm{C}$ ), which resulted in higher IOPs in one eye. The visual prognosis, however, was poor in these eyes, since all three had significant visual acuity loss from preoperative measurements.

\section{Discussion}

In 1983, Chen ${ }^{14}$ reported the first attempt to use mitomycin as an adjunct chemotherapy in glaucoma surgery. Since then, several authors have investigated the effect of topical intraoperative mitomycin $\mathrm{C}$ in glaucomatous eyes with poor surgical prognosis. ${ }^{15161921}$ All these studies suggested that mitomycin $\mathrm{C}$ is highly effective in increasing the success rates of trabeculectomy in eyes with poor surgical prognosis.

Previous studies suggested that 30 to $100 \%$ of patients undergoing combined extracapsular cataract extraction, posterior chamber intraocular lens implantation, and trabeculectomy showed successful IOP control without use of antiglaucoma medication postoperatively. ${ }^{23-34}$ However, the length of follow up, the sample size, the success criteria, and the nature of the studies (retrospective $v$ prospective) were different. Most of the authors did not consider alternative success criteria for eyes with preoperative intraocular pressure lower than $21 \mathrm{~mm}$ $\mathrm{Hg}$, which may have artificially increased their success rates.

In this series, $93 \cdot 3 \%$ of the eyes of the combined procedure group showed successful control of IOP without supplementary antiglaucoma medication. The only eye considered to be a failure had a preoperative IOP at $15 \mathrm{~mm} \mathrm{Hg}$, and the postoperative reduction in IOP was less than $30 \%$ of the preoperative value. The visual outcome was also satisfactory. All but two eyes showed a significant improvement in visual acuity from preoperative values.

Edwards $^{23}$ observed that the results of combined procedure in eyes with secondary glaucoma are less encouraging than in eyes with primary glaucomas. After 6 months of follow up, six of 11 eyes $(55 \%)$ with secondary glaucoma showed controlled IOPs without antiglaucoma medication, compared to an $81 \%$ success rate in eyes with primary glaucomas. In our series, all four eyes with poor surgical prognosis were considered complete successes after a mean follow up of 6.8 months.

Hennis and Stewart ${ }^{35}$ investigated the effects of postoperative 5-FU injections following com- 
bined procedures. After 3 months of surgery, mean IOPs of the 5-FU treated eyes and the controls were similar, as well as the mean number of postoperative antiglaucoma medications. The authors concluded that the use of 5-FU in patients who underwent combined trabeculectomy and extracapsular cataract extraction had no beneficial effect. Recently, Zeiter et al performed a randomised, prospective study to investigate the efficacy of mitomycin C in combined procedures (Zeiter JH, Juzych MS, Shin DH. Adjunctive subscleral flap mitomycin in trabeculectomy combined with cataract surgery. Presented as a paper at the American Academy of Ophthalmology Annual Meeting, Dallas, 1992). After a follow up of 3 months, the mean IOP and number of antiglaucoma medications were similar between the treated and control eyes. The authors concluded that there was no beneficial effect of adjunctive subscleral mitomycin $C(0.5 \mathrm{mg} / \mathrm{ml})$. However, the beneficial effect of subconjunctival mitomycin $C$, as used in our series, was not evaluated.

Patients who present with progressive visual field loss and severe optic nerve damage are felt to need low postoperative IOP to prevent further glaucomatous damage. A variety of studies investigated the use of postoperative 5-FU in patients with uncomplicated glaucoma in whom primary trabeculectomies were performed. ${ }^{36-41}$ All of them confirmed that success rates (some of them reaching $100 \%$ ) were significantly higher in eyes treated with 5-FU. However, complications such as corneal erosions and conjunctival wound leaks were more frequent in the 5-FU treated eyes.

This study is, to our knowledge, the first to report the results of intraoperative mitomycin C in a large series of patients undergoing intraocular surgery for the first time. Mitomycin $\mathrm{C}$ proved to be highly effective in successfully reducing IOP in eyes with advanced glaucomatous damage. The success rate observed in this series $(97 \cdot 4 \%)$ compares favourably with those obtained with 5-FU injections. ${ }^{36-11}$ After a mean follow up of 6.7 months, the mean IOP reduction in this group was $17.4 \mathrm{~mm} \mathrm{Hg}$ (64\% of mean preoperative IOP), and only one of 38 patients whose IOP was successfully controlled required one antiglaucoma medication. Furthermore, $89 \cdot 7 \%$ showed IOPs in the low teens (lower than $15 \mathrm{~mm}$ $\mathrm{Hg}$ ) at the last follow up.

Most of the complications observed in this study seemed to be secondary to one basic problem: excessive filtration. Among the 71 eyes, $15(21 \cdot 1 \%)$ developed choroidal detachments and nine $(17 \cdot 6 \%)$ developed shallow anterior chambers postoperatively. Some of these detachments developed late in the postoperative period, showing that an important amount of filtration was still present. The development of choroidal detachments and shallow anterior chambers in the postoperative period are known to be associated with the development of lens opacification. This association was observed in four of the eight patients who developed cataract following surgery.

The occurrence of hypotony maculopathy (three cases) can also be correlated to excessive filtration. Cases of hypotony maculopathy, a rare complication of filtration surgery (Costa VP, Smith M, Spaeth GL, Gandham S, Markovitz B. Loss of visual acuity after trabeculectomy. Presented as a paper at the American Academy of Ophthalmology Annual Meeting, Dallas, 1992), have recently been described following intraoperative application of mitomycin C. ${ }^{14214243} \mathrm{It}$ is thought that, in some eyes, hypotony leads to inward movement of the scleral wall, resulting in chorioretinal wrinkling, disc swelling, and vascular tortuosity. ${ }^{44}$ The chorioretinal folds in the macular area and retinal pigment epithelium changes seen in a later stage of the process are responsible for the visual acuity loss. Stamper $e$ $a l^{45}$ described eight cases of hypotony maculopathy following filtration surgeries with postoperative 5-FU injections. Comparing these patients with patients who developed prolonged hypotony without maculopathy, the authors suggested that young age and myopia may be risk factors for the development of hypotony maculopathy. In our series, two of the three eyes were myopic and showed a hyperopic shift due to the chorioretinal wrinkling. When exposed to ocular hypotony, the thinner sclera of a myopic eye may not offer the required resistance to avoid the inward collapse of the scleral wall, leading to chorioretinal folds.

Postoperative loss of visual acuity, observed in $28 \cdot 2 \%$ of the eyes in the primary trabeculectomy group, may also be understood as an indirect consequence of excessive filtration, since the causes of visual loss were cataract formation and hypotony maculopathy.

Corneal epithelial defects and conjunctival wound leaks, complications typically associated with postoperative 5-FU injections, were rarely seen in this series. However, the occurrence of thin, ischaemic, cystic blebs after intraoperative mitomycin $\mathrm{C}$ was very common. The development of late endophthalmitis has been associated with thin blebs. ${ }^{46}$ A long term follow up of patients who receive intraoperative application of mitomycin $C$ is necessary to investigate the incidence of this potentially devastating complication.

The excessive filtration obtained after intraoperative mitomycin $\mathrm{C}$ is secondary to its significant inhibitory effect on wound healing. While 5-FU acts primarily in cells which are in the $S$ phase of the cell cycle, mitomycin $C$ seems to be active against all cells, regardless of the phase of the cell cycle. ${ }^{47}$ Therefore, even cells not actively synthesising DNA are affected by mitomycin $\mathrm{C}$ and do not proliferate after the exposure. This may explain why mitomycin $\mathrm{C}$ is more effective in inhibiting fibroblast proliferation than 5-FU.

This study suggests that mitomycin $\mathrm{C}$ is a potent wound healing inhibitor, highly effective in preventing scarring of the filtration blebs in eves with uncomplicated glaucoma operated for the first time, and eyes which undergo combined cataract/glaucoma surgery. Recently, it has been shown ${ }^{47}{ }^{48}$ that short exposures to low doses $(0.01$ to $0.2 \mathrm{mg} / \mathrm{ml}$ ) of mitomycin $\mathrm{C}$ are effective in inhibiting human fibroblast proliferation in vitro. Reducing the dosage and the time of exposure to this drug might be a reasonable way to reduce the excessive amount of filtration 
observed following the use of topical mitomycin $\mathrm{C}$ in glaucoma filtration surgery. Employing a larger number of sutures in the scleral flap and lasering them in the postoperative period may also allow a gradual increase in outflow.

The use of intraoperative mitomycin $\mathrm{C}$ $(0.4 \mathrm{mg} / \mathrm{ml})$ in relatively uncomplicated cases may be associated with unacceptable risks of hypotony and its consequences. We suggest that the indications of mitomycin $\mathrm{C}$ should be limited to eyes in which the surgical prognosis is poor, or an intraocular pressure in single figures is desired (that is, low tension glaucoma, advanced primary open angle glaucoma).

1 Gressel MG, Parrish RK II, Folberg R. 5-Fluorouracil and glaucoma filtering surgery. I: An animal model. Ophthal mology 1984; 91: 378-83.

2 Heuer DK, Parrish RK II, Gressel MG, Hodapp E, Palmberg PF, Anderson DR. 5-Fluorouracil and glaucoma filtering

3 Knapp A, Heuer DK, Stern GA, Driebe WT. Serious corneal complications of glaucoma filtering surgery with postopera-
tive 5-fluorouracil. Am $\mathcal{F}$ Ophthalmol 1987; 103: 183-7.

4 The Fluorouracil Filtering Surgery Study Group. Fluorouracil filtering surgery study: One-year follow-up. Am $\mathcal{F}$ Ophthalfiltering surgery study:

5 Crooke ST, Bradner WT. Mitomycin C: a review. Cancer Treat Rev 1976; 3: 121-39.

6 Verweij J, Pinedo HM. Mitomycin C: mechanism of action, usefulness and limitations. Anti-Cancer Drugs 1990; 1: 5-13.

7 Yamamoto T, Varani J, Soong HK, Lichter PR. Effect of 5 fluorouracil and mitomycin $\mathrm{C}$ on cultured rabbit subconjunctival fibroblasts. Ophthalmology 1990; 97: 1202-10.

8 Choon LK. The pterygium and mitomycin-C therapy. Med $\mathcal{F}$ Malaysia 1976; 31: 69-72.

9 Chayakul V. Prevention of recurrent pterygium in mitomycin C. Fortschr Ophthalmol 1987; 84: 422-4.

10 Hayasaka S, Noda S, Yamamoto Y, Setogawa T. Postoperative instillation of low dose mitomycin $\mathrm{C}$ in the treatment of primary pterygium. Am $\mathcal{F}$ Ophthalmol 1988; 106: 715-8.

11 Singh G, Wilson MR, Foster CS. Mitomycin eye drops as treatment for pterygium. Ophthalmology 1988; 95: 813-21.

treatment for pterygium. Ophthalmology 1988; 95: 813-21.
12 Singh G, Wilson MR, Foster CS. Long-term follow-up study of mitomycin eye drops as adjunctive treatment for pterygia and its comparison with conjunctival autograft transplantation. Comea 1990; 9: 331-4.

13 Hayaska S, Noda S, Yamamoto Y, Setogawa T. Postoperative instillation of mitomycin $\mathrm{C}$ in the treatment of recurren pterygium. Ophthalmic Surg 1989; 20: 580-3.

$14 \mathrm{Chen} \mathrm{CW}$. Enhanced intraocular pressure controlling effectiveness of trabeculectomy by local application of mitomycin C. Trans Asia-Pacific Acad Ophthalmol 1983; 9. 172-7.

15 Chen CW, Huang HT, Bair JS, Lee CC. Trabeculectomy with simultaneous application of Mitomycin C in refractory glaucoma. F Ocul Pharmacol 1990; 6: 175-82.

16 Palmer SS. Mitomycin as adjunct chemotherapy with trabeculectomy. Ophthalmology 1991; 98: 317-21.

17 Charles JB, Ganthier R, Wilson MR, Lee DA, Baker RS Leong KW, et al. Use of bioerodible polymers impregnated with mitomycin in glaucoma filtration surgery in rabbits. with mitomycin in glaucoma filt

18 Wilson MR, Lee DA, Baker RS, Goodwin LT, Wooten F. The effects of topical mitomycin on glaucoma filtration surgery in rabbits. F Ocul Pharmacol 1991; 7: 1-8.

19 Kitazawa Y, Kawase K, Matsushita H, Minobe M. Trabeculectomy with mitomycin - a comparative study with fluorouracil. Arch Ophthalmol 1991; 109: 1693-8.

20 Plasquale LR, Thibault D, Dorman-Pease ME, Quigley HA Jampel HD. Effect of topical mitomycin C on glaucoma
filtration surgery in monkeys. Ophthalmology 1992; $99: 14$ 8.

21 Skuta GL, Beeson CC, Higginbotham EJ, Lichter PR, Musch DC, Bergstrom TJ, et al. Intraoperative mitomycin versus postoperative 5-fluorouracil in high risk glaucoma filtering surgery. Ophthalmology 1992; 99: 438-44.

22 Cairns JE, Trabeculectomy. Trans Am Acad Ophthalmol Otolaryngol 1972; 76: 384-91.
23 Edwards RS. Trabeculectomy combined with cataract extraction: a follow up study. Brf Ophthalmol 1980; 64: 720-4.

24 Percival SPB. Glaucoma triple procedure of extracapsular cataract extraction, posterior chamber lens implantation, and trabeculectomy. BrF Ophthalmol 1985; 69: 99-102.

25 Jay JL. Extracapsular lens extraction and posterior chambe intraocular lens insertion combined with trabeculectomy. $B$ fOphthalmol 1985; 69: 487-90.

26 Shields MB. Combined cataract extraction and guarded sclerectomy. Reevaluation in the extracapsular era. Ophthalmology 1986; 93: 366-70.

27 Simmons ST, Litoff D, Nichols DA, Sherwood MB, Spaeth GL. Extracapsular cataract extraction and posterior chamber lens implantation combined with trabeculectomy in patients with glaucoma. Am $\mathcal{F}$ Ophthalmol 1987; 104: 46570 .

28 McCartney DL, Memmen JE, Stark WJ, Quigley HA, Maumenee AE, Gottsch JD, et al. The efficacy and safety of and intraocular lens implantation. Ophthalmology 1988; 95: and intraor $754-63$.

29 Raitta C, Tarkkanen A. Combined procedure for the management by glaucoma and cataract. Acta Ophthalmol 1988; 66: 667-70.

30 Williamson TH, Bacon AS, Flanagan DW, Jakeman CM Jordan K. Combined extracapsular extraction and trabeculectomy using a separated corneal section. Eye 1989; 3: 547-

31 Naveh N, Kottass R, Golvinski J, Blumenthal M, Bar-Sever D. The long-term effect on intraocular pressure of a procedure combining trabeculectomy and cataract surgery, as compared with trabeculectomy alone. Ophthalmic Surg 1990; $21: 339-45$.

32 Longstaff S, Wormald RP, Mazover A, Hitchings RA Glaucoma triple procedures: efficacy of intraocular pressure Glaucoma triple procedures: efficacy of intraocular pressure 93.

33 Pasquale LR, Smith SG. Surgical outcome of phacoemulsification combined with the Pearce trabeculectomy in patients with glaucoma. F Cataract Refract Surg 1992; 18: 301-5.

34 Gregg FM. Phacoemulsification and modified trabeculectomy for managing combined cataracts and glaucoma. $\mathcal{F}$ Cataract Refract Surg 1992; 18: 362-5.

35 Hennis HL, Stewart WC. The use of 5-fluorouracil in patients following combined trabeculectomy and cataract extraction. Ophthalmic Surg 1991; 22: 451-4.

36 Liebmann JM, Ritch R, Marmor M, Nunez J, Wolner B. Initial 5-fluorouracil trabeculectomy in uncomplicated glaucoma. Ophthalmology 1991; 98: 1036-41.

37 Taniguchi T, Kitazawa Y, Shimizu U. Long-term results of 5-fluorouracil trabeculectomy for primary open-angle S-fluorouracil trabeculectomy for prim

38 Watanabe J, Iwata K, Sawaguchi S, Nanba K. Trabeculectomy with 5-fluorouracil. Acta Ophthalmol 1991; 69: 455-61.

39 Wilson RP, Steinmann WC. Use of trabeculectomy with postoperative 5-fluorouracil in patients requiring extremely low intraocular pressure levels to limit further glaucom progression. Ophthalmology 1991; 98: 1047-52.

40 Ophir A, Ticho U. A randomized study of trabeculectomy and subconjunctival administration of fluorouracil in primary glaucomas. Arch Ophthalmol 1992; 110: 1072-5.

41 Whiteside-Michel J, Liebmann JM, Ritch R. Initial 5fluorouracil trabeculectomy in young patients. Ophthal mology 1992; 99: 7-13.

42 Schwartz AL, Weiss HS. Bleb leak with hypotony after lase suture lysis and trabeculectomy with mitomycin C (Letter) Arch Ophthalmol 1992; 110: 1049.

43 Jampel HD, Pasquale LR, Dibernardo C. Hypotony maculopathy following trabeculectomy with mitomycin C (Letter) Arch Ophthalmol 1992; 110: 1049.

44 Gass JDM. Hypotony maculopathy. In: Bellows JG, ed Contemporary ophthalmology: honoring Sir Stewart Duke Elder. Baltimore: Williams \& Wilkins, 1972: 343-66.

45 Stamper RL, McMenemy MG, Lieberman MF. Hypotonous maculopathy after trabeculectomy with subconjunctival 5 fluorouracil. Am F Ophthalmol 1992; 114: 544-53.

46 Wolner B, Leibmann JM, Sassani JW, Ritch R, Speaker M Marmor M. Late bleb-related endophthalmitis afte trabeculectomy with adjunctive 5-fluorouracil. Ophthalmology 1991; 98: 1053-60.

47 Jampel HC. Effect of brief exposure to mitomycin $C$ on viability and proliferation of cultured human Tenon's capsule fibroblasts. Ophthalmology 1992; 99: 1471-6.

48 Khaw PT, Sherwood MB, Mackay SLD, Rossi MJ, Schultz G. Five-minute treatments with fluorouracil, floxuridine, and mitomycin have long-term effects on human Tenon's capsule fibroblasts. Arch Ophthalmol 1992; 110: 1150-4. 